Acta Hispanica (2019) 24: 77-86

\title{
LA GENEALOGÍA Y VIDA DEL SACERDOTE AGUSTINO FULGENTIUS RODRIGUEZ DEL BANATO
}

\author{
BÉLA BARSI \\ Instituto Nacional de Psiquiatría y Adicciones Nyírő Gyula, Budapest
}

\begin{abstract}
Resumen: El estudio recopila, a base de documentos entrelazados como una especie de mosaico, la vida del sacerdote ya conocido de la obra anterior del autor, dedicada a la historia de la familia Rodriguez (Rodrich) que se había instalado en el Banato. Como resultado de los estudios y la perseverancia, a pesar de los obstáculos de la época, el hijo de una familia española inmigrante, logró convertirse en una persona eclesiástica honorable, tal y como lo guarda la tradición oral familiar. La inscripción sobre su defunción en Mistelbach puede servir como punto de partida para una futura investigación sobre la familia Rodriguez, por lo tanto, el autor hará un intento de remontar hasta las raíces de la familia en España.
\end{abstract}

Palabras clave: exsacerdote agustino, ballestero, la roda, genealogía

Abstract: This study describes the life of a priest on the basis of mosaic-like documents. The priest can be familiar from the author's earlier publication in which he wrote the history of the Rodriguez (Rodrich) family lived in Bánát. Successfully overcoming the difficulties of the era, he became -according to the oral tradition of the Rodriguez family- a prestigious member of the clergy, thanks to his diligence and perseverance. His Mistelbach death certificate can serve as a further starting point for the origins of the family in Spain.

Keywords: Ex-priest Augustine, Ballestero, Rode, Genealogy

A lo largo del territorio del Banato iban apareciendo cada vez más españoles, por un lado, emigrantes, y, por otro lado, descendientes de los soldados en los siglos XVII y XVIII durante las guerras contra los turcos y también en la época que las siguió. Al no tener la posibilidad de adquirir tierra, en la sociedad feudal basada en la posesión de tierras, su única manera de sobrevivir en el entorno social forjado tras la destrucción por los turcos era el aprendizaje y la adaptación. De este modo echó sus raíces la familia Rodriguez (Rodrich), cuyos miembros desempeñaron oficios tanto en el ámbito militar, como en la esfera pública y en la vida eclesiástica. Muchos de ellos y de sus descendientes son conocidos gracias al trabajo de los historiadores (Réti, 1890; Miletz, 1878; Fallenbüchl, 1979; Alcoberro, 2002; Anderle, 2013) que investigan la vida de los españoles en Hungría en el siglo XVIII.

Fulgentius Rodriguez, que aparece en el artículo anterior del autor (La Historia de la Familia Rodriguez/Rodrigues) también aparece en el artículo de Ferenc Fallenbüchl (El orden de monje de Agostino en Hungría). Sin embargo, en la investigación del autor, fue una figura clave desde un principio, y también fue tomada en consideración a la hora de 
La genealogía y vida del sacerdote Agustino Fulgentius Rodriguez del Banato

encontrar el ascendiente español (Antonio de Rodriguez) siendo el tío del cirujano (señorial) Carolus Rodriguez.

Al principio del siglo XVIII el soldado mercenario Antonio de Rodriguez luchó contra los turcos en el regimiento de Alcaudete primero como teniente y después como capitán. Su regimiento fue destinado a Orsova donde, tras establecer a su familia (su hijo Joseph nació en 1717), halló su muerte en el campo de batalla. Hasta el día de su muerte participaba en la administración de la zona de la frontera militar. El prefecto de Mehadia en el distrito de Orsova, Joannes de Rodrich, fue uno de sus descendientes. Los hijos de los Rodriguez estudiaron en el instituto de Escolapios de Pest. Entre ellos estaba Antón Rodriguez también que más adelante decidió convertirse en fraile escogiendo el nombre Fulgentius.

Los numerosos datos de historia eclesiástica e historia de la cultura que fueron hallados a lo largo de la investigación del autor, hacen posible la escritura de la biografía y la investigación de la genealogía de Fulgentius, mientras uno de esos datos, que identifica su persona, sustenta sin ninguna duda la hipótesis del autor sobre el origen de la familia Rodriguez, desarrollada en su artículo anterior.

En un principio Fulgentius Rodriguez, en la investigación de la familia Rodriguez, apareció sin nombre, solamente se le mencionó como una persona eclesiástica reconocida (el tío de Carolus Rodriguez) que vivía en Milán. A base de la investigación del autor se conoce que de verdad vivía un párroco llamado Giuseppe Rodriguez en la ciudad de Como, pero no era pariente.

Durante la investigación sobre el ascendiente Rodriguez, la cual se desarrolló en el Archivo Nacional de Hungría, en el castillo de Buda, y que se centró principalmente en el cirujano Carolus Rodriguez, inesperadamente pasó a primer plano un documento que hacía referencia a Fulgentius Rodriguez, que anteriormente había sido monje agustino.

El Acta Generalia (desde 1770 hasta 1848) contiene los documentos de la Cancillería, al que se accede a través del Protocollum Exhibitorium (C2), cuyo registro alfabético contiene el nombre de Fulgentius Rodriguez (MNLOL, Protocollum Exhibitorium C2, Carrete de película No. 19259). El documento que aparece en el Acta Generalia, se trata de la petición de Fulgentius Rodriguez sobre el asunto de la compensación de su pensión (MNLOL, Acta Generalia, Documento con el número de referencia A39/1285). La orden de José II del año 1782 que abolió ciertas órdenes religiosas, fue un golpe duro para los agustinos. En Hungría, tras la gloriosa reconquista de Buda, la orden se reorganizó, aprovechando que el artículo 50 de la ley del año 1729 lo había legalizado. Sin embargo, apenas pudo entrar en funciones cuando de nuevo se vio obstaculizada por el josefinismo. Los monjes ermitaños de la orden de San Agustín 
solamente pudieron restaurar unos pocos de sus monasterios, entre los cuales el monasterio de Buda fue el más significativo. El 21 de marzo de 1785 se promulgó la orden sobre el cierre del monasterio agustino de Buda. El prior Felicián P. Háusler, el superior István P. John, el predicador dominical Jordán P. Lutz, el vice párroco Kázmér P. Rádl y el predicador de días festivos Lipót P. Pamer, acataron la orden, al igual que Fulgent P. Rodriguez, perteneciente al convento de Graz (St. Johann bei Herberstein), quien permanecía allí en ese momento, y debido al carácter integral de la orden, también se vio afectado. Los agustinos fueron reemplazados por franciscanos en el monasterio. El traspaso del monasterio se realizó tras levantar un estricto inventario económico. Los agustinos, aceptando la orden de Su Majestad, se sometieron a ello, sin embargo, como no tenían esperanzas de tener residencia permanente y segura en los monasterios de otras órdenes, solicitaron que los miembros de la orden pudieran alquilar alojamiento por su cuenta y pudieran vivir fuera de los monasterios. Muchos de ellos se vieron obligados a cambiar radicalmente su estricta vida ermitaña. Además, su existencia también corría peligro, por lo cual, muchos de ellos acabaron ejerciendo su profesión como clero secular.

De este modo el Pater Lipót se convirtió en clero secular en Korneuburg, y Fulgent Rodriguez se trasladó a Bruck an der Leitha por Ferenc Fallenbüchl. Sin embargo, es probable que también haya permanecido un tiempo en Pécs. Durante su investigación el autor encontró un documento sobre el hecho de que un párroco llamado Antonius Roderich oficiaba matrimonios en 1799 en la parroquia de la iglesia del centro de la ciudad de Pécs, según se ve en la imagen de abajo (Family History Library Catalog. Carrete de película No. 7993450, imagen No. 349). Es probable su identidad con Fulgentius.

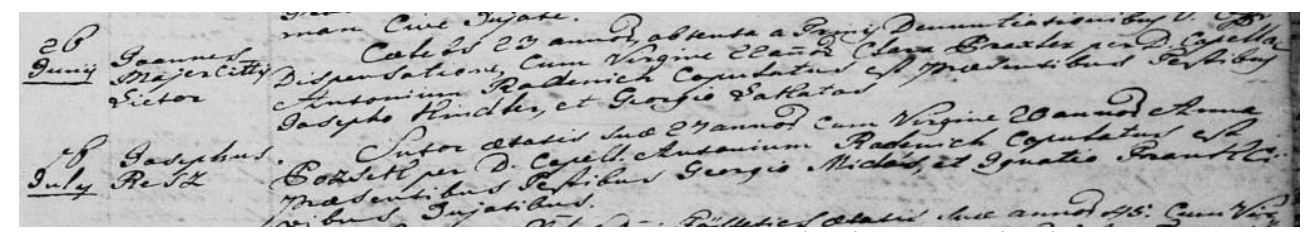

Tabla 1. Antonius Roderich oficia matrimonios (26/06/1799 y 16/07/1799, Pécs)

Temporalmente le acogió entre sus miembros la orden de San Agustín de Völkermarkt y desde allí mandó su petición a la Cancillería con respecto a su pensión. Tras la anulación de las órdenes por el Emperador, como respuesta a su petición, Rodriguez Fulgentius recibió como compensación la pensión de 10 años y 3 meses en 1798. La petición es especialmente interesante, puesto que en la parte superior de la hoja se puede leer la palabra Lovasb, la abreviación de Lovasberény. Fulgentius mandó su carta de Völkermarkt a Lovasberény, al conde Antal Cziráky, que, al tener un cargo de confianza, pudo intervenir a su favor. 
La genealogía y vida del sacerdote Agustino Fulgentius Rodriguez del Banato

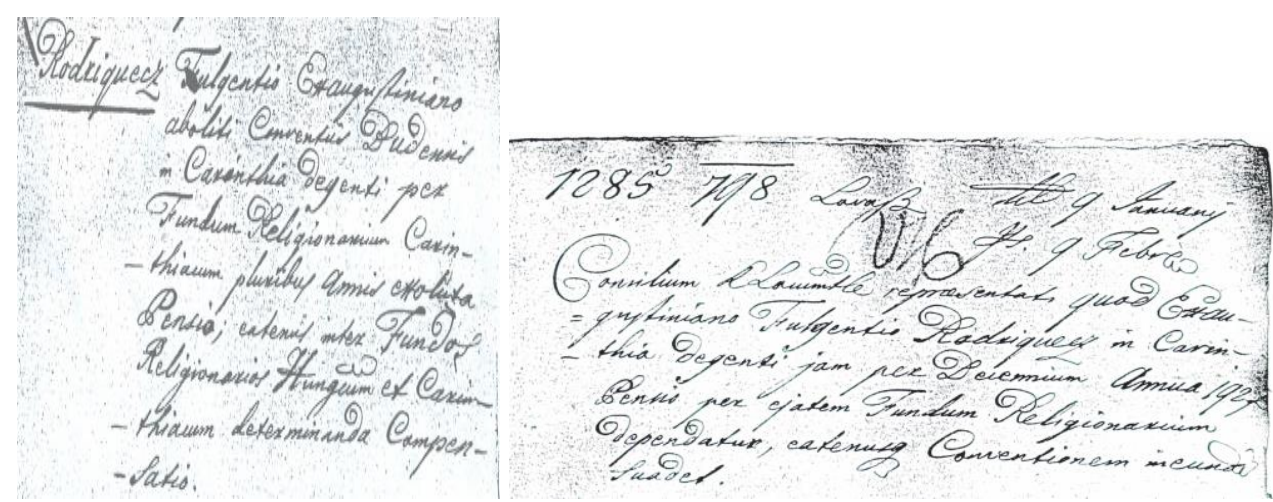

Tabla 2. Fragmento de la petición de Fulgentius Rodriguez
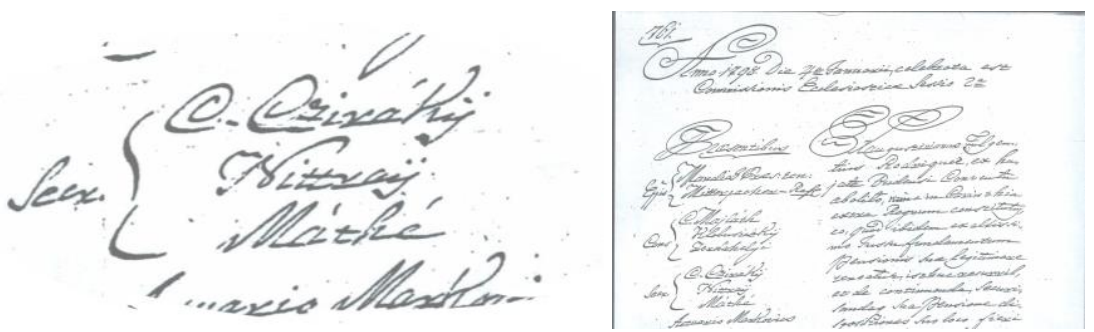

Tabla 3. Fragmento de la petición de Fulgentius

Es probable que en aquel entonces Carolus Rodriguez ya frecuentara el señorío de Lovasberény. En el documento No. 20002 (Magyar Nemzeti Levéltár Országos Levéltár, Acta Generalia, Carrete de película No. 17815) es claramente legible el nombre de la ciudad carintia Völkermarkt, desde donde Fulgentius escribió su petición con letra gótica.
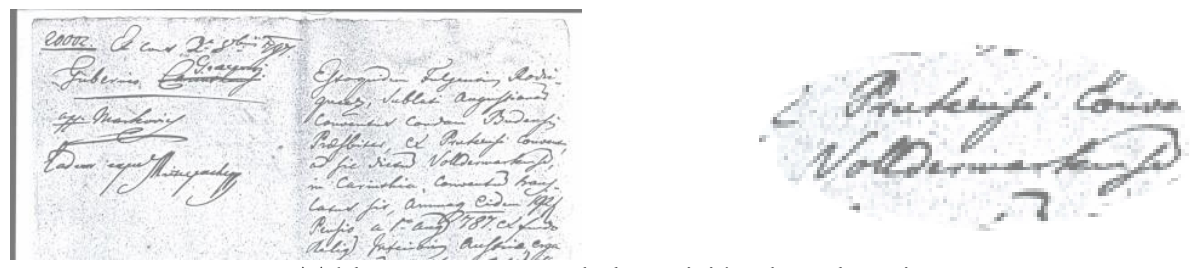

Tabla 4. Fragmento de la petición de Fulgentius

La petición que fue mandada en 1797 desde el monasterio de Völkermarkt al Consejo Lugarteniente Real Húngaro también contenía un anexo escrito en latín, que valoraba muy positivamente la labor que ejercía el monje Fulgentius en Carintia, donde también enseñaba catequismo en una escuela de Gentifor. 
Béla Barsi

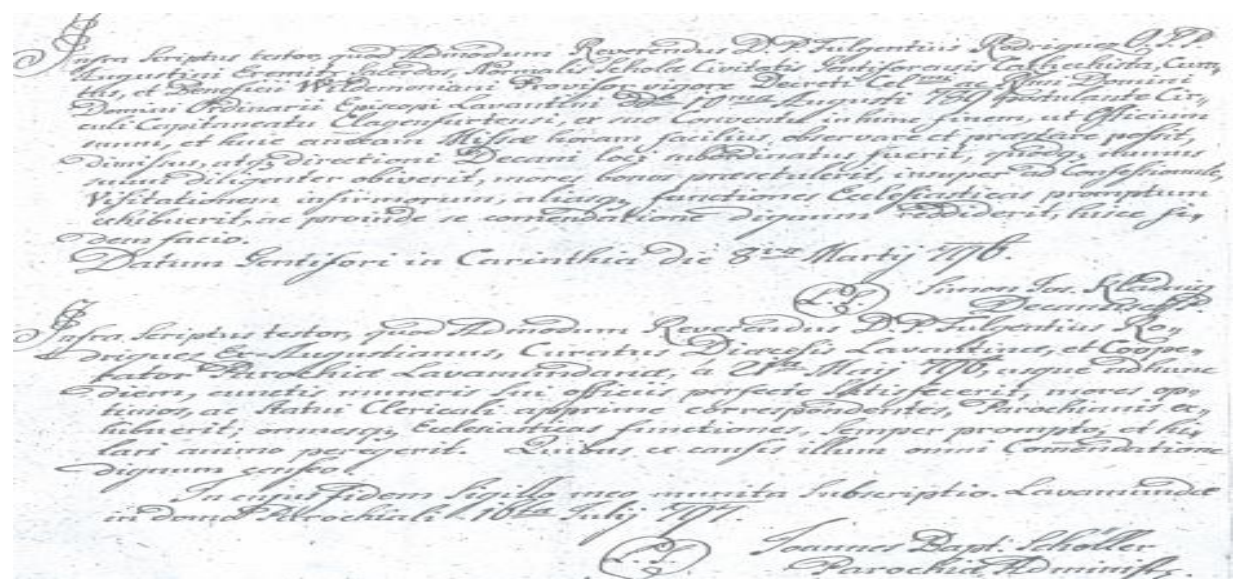

Tabla 5. El anexo de la petición de Fulgentius.

Su petición fue apoyada también por la Diócesis de Klagenfurt. Christine Tropper contestó (Archiv der Diözese Gurk Zl: A-98106, Fragmento de la lista de nombres de los frailes de Völkermarkt y la carta de Christine Tropper) la carta que el autor había mandado a la Diócesis de Klagenfurt, y también adjuntó el elenco de los monjes del monasterio agustino de Völkermarkt de aquella época, entre los cuales estaba Fulgentius Rodriguez.

Según una descripción breve, en 1789 tenía 34 años, hablaba húngaro y alemán, enseñaba catequismo y estudió teología.

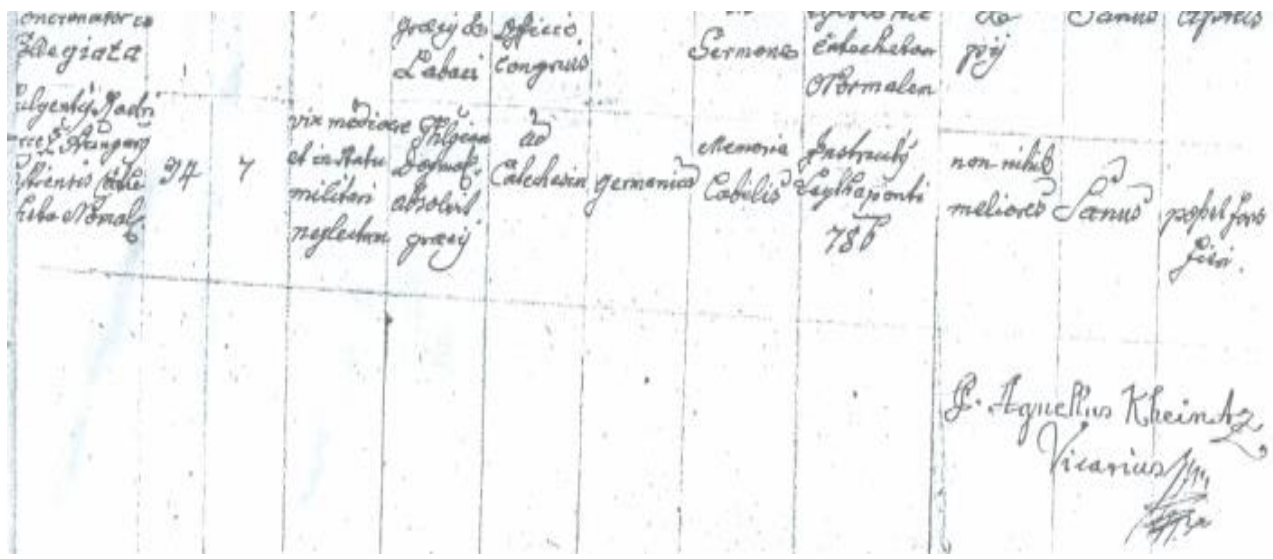

Tabla 6. El elenco y descripción de los monjes de Völkermarkt 
La genealogía y vida del sacerdote Agustino Fulgentius Rodriguez del Banato

En el archivo de la Diócesis de Graz también apareció el documento sobre su ordenación en 1782. Este documento fue lo que le permitió ejercer su profesión como clero secular más adelante.

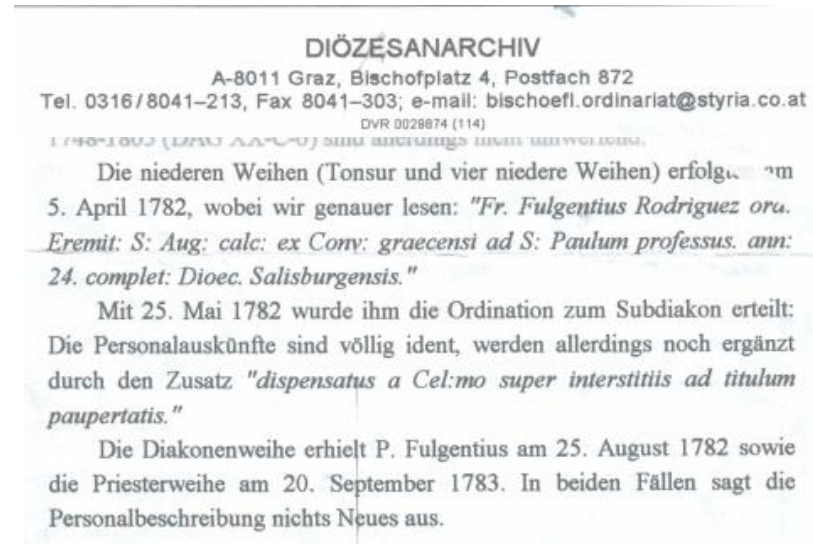

Tabla 7. La ordenación de Fulgentius Rodriguez

El archivero József Mihály Kiss (del Archivo Ludovika) también dio un nuevo impulso a la investigación, ya que tiempo atrás había hecho una indagación sobre los alumnos húngaros que habían estudiado en universidades extranjeras. Examinó si entre los alumnos de la Josephinum figuraba Carolus Rodriguez. Sin embargo, a base de sus notas resultó que no, aunque en 1781, en Viena estudió teología un alumno húngaro, de buena familia, de origen de Timisoara, llamado Antón Rodriguez.

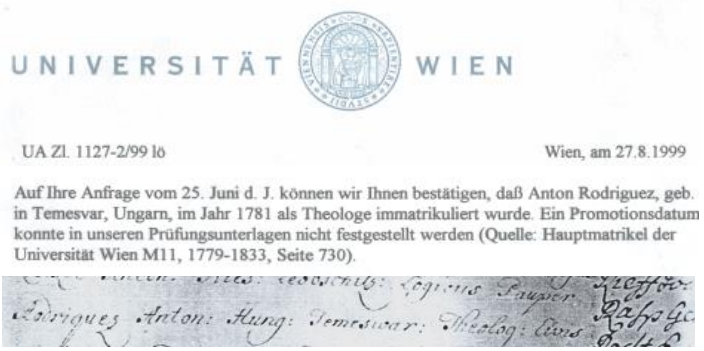

Tabla 8. Los estudios de teología de Fulgentius (Antón) Rodriguez

Por consecuencia, Antón y Fulgentius Rodriguez es la misma persona, y el nombre Fulgentius es su nombre de fraile, lo que viene justificado en el estudio de Ferenc Fallenbüchl, en el que escribe sobre las circunstancias de la disolución de la orden religiosa de Buda, y en el que el nombre de Fulgent Rodriguez viene mencionado varias veces. El conocimiento del nombre facilitó el proseguimiento de la investigación. 
Nació en 1754, con el nombre Antonius, que luego cambió a Antón, y al final ya solo utilizaba su nombre de fraile. Desafortunadamente, ni siquiera tras una investigación exhaustiva se ha podido identificar el lugar exacto de su nacimiento (Pest o Timisoara), ya que no se ha podido revelar su matrícula. La razón de esto se debe al hecho de que los españoles, a la hora de celebrar bautizos o matrimonios, recurrían frecuentemente a sus propios curas.

En ese momento la examinación del legado de historiador de Fallenbüchl aportó un hilo nuevo (Fallenbüchl Zoltán történetírói hagyatéka Fővárosi Levéltár HU XIV. 67). Él fue el primero en mencionar que la familia originaria del Banato, particularmente el escritor y director de radio Ödön Rodriguez y el director de cine Endre Rodriguez. La familia y parentela de János Károly de Rodrich, prefecto de la frontera militar, que se instaló en el Banato, según la investigación del autor también son descendientes del inmigrante español, Antonio de Rodriguez. La familia se preocupó por los estudios de sus hijos. En su artículo Fallenbüchl destacó el Instituto de Escolapios de Pest, donde varios alumnos españoles habían estudiado, y tras la examinación de su legado esto se clarificó aún más.

En aquel entonces en Timisoara no existía Instituto de Escolapios. Afortunadamente, la matrícula del Instituto de Escolapios de Pest contiene numerosos datos importantes sobre los alumnos españoles que habían estudiado allí (Matrícula escolar del instituto de escolapios de Pest, 1761-1765:41, 65.) Entre ellos figuran Joseph y Antonio Rodriguez también, de los cuales Joseph probablemente era ascendiente directo del cirujano Carolus Rodriguez, y Antonio es el posterior Fulgentius Rodriguez, lo que se confirma al comparar la matrícula del instituto con el acta de defunción de Fulgentius (véase más abajo).

Según la anotación que se refiere a Antonio en la matrícula del instituto del 1764 y 65, en esos años tenía 10 y 11 años, por lo tanto, nació en 1754, lo que coincide con la fecha del nacimiento de Fulgentius. En algunas de las anotaciones donde aparece su nombre, este va acompañado por el atributo hispanus nobilis y de Ballestero. En dos de las anotaciones también figuran los atributos pestamus y pestiensis, que podían significar su residencia por aquel entonces, pero también su lugar de nacimiento.

En el caso de que sea verdad, y es muy probable que lo sea, Fulgentius era la misma persona que celebraba matrimonios en Pécs con el nombre de Antal Roderich, lo que sustenta su origen de la familia Roderich del Banato (ya se habían visto varios ejemplos del cambio de nombre temporalmente entre Rodriguez y Roderich). 

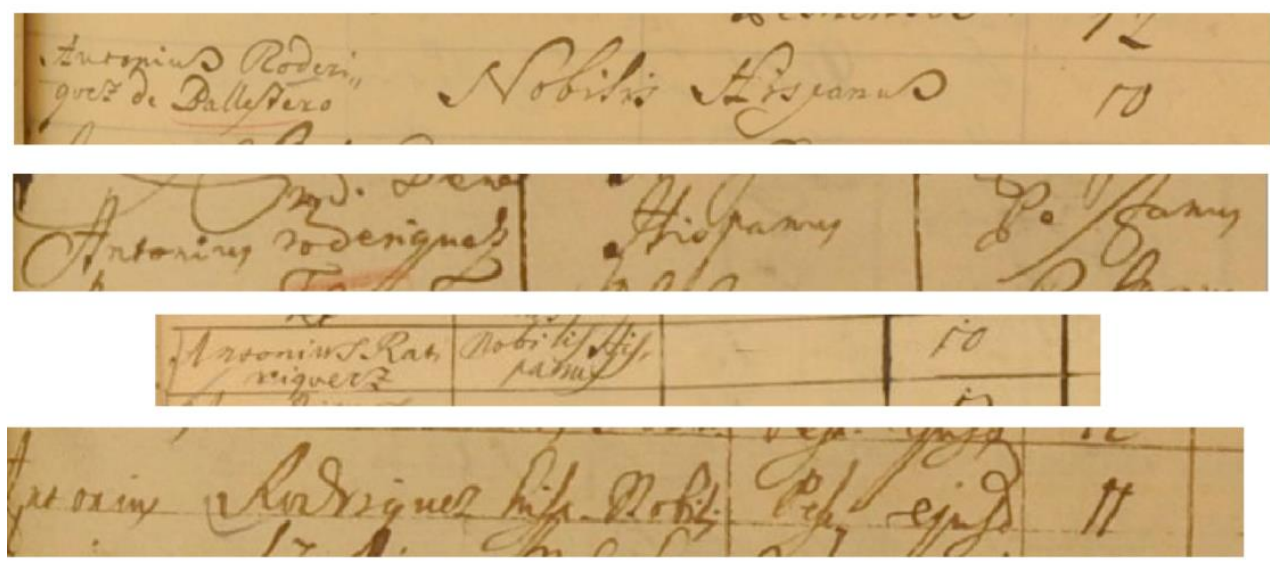

Tabla 9. Fragmento de la matrícula del Instituto de Escolapios de Pest

Gracias a la información proporcionada por Peter Tropper (comunicado del 12 de junio de 2018. Diócesis de Klagenfurt) se pudo continuar siguiendo la vida de Fulgentius Rodriguez. Hasta el año 1796 había sido párroco en Lavamünd, y también ejercía su profesión en Wölfnitz, en Witseldorf y en Mistelbachban (Personalstand der Sek.-und Reg-Geistlichkeit der Fürsterbishcöflichen Wiener-Disözese, 1837, y personalstand der Konz. Und der. Gesamten Welt-und Klosters, 1837). Según el dato que facilitó Johann Weißensteiner (Archivo de la Diócesis de Viena), este último fue el lugar donde había fallecido el 18 de abril de 1835, a los 81 años.

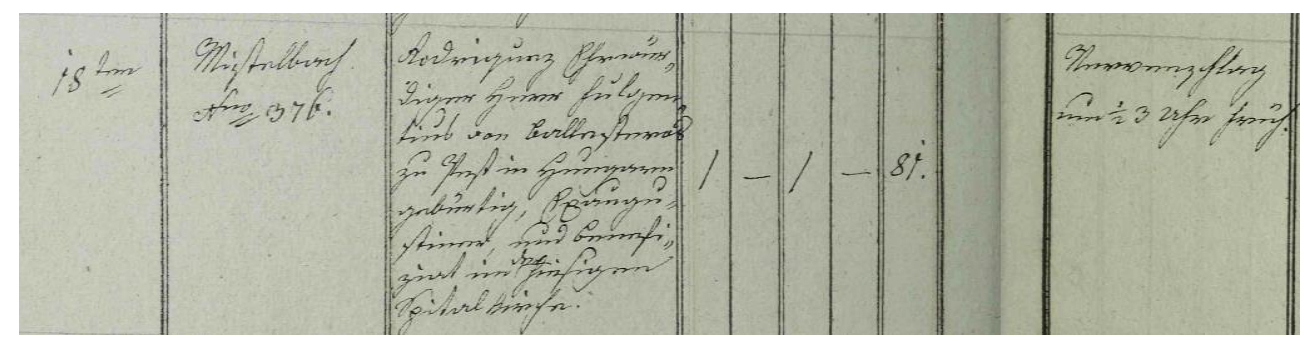

Tabla 10. Fragmento del registro funerario de la parroquia de Mistelbach N376

Según la inscripción sobre su defunción era originario de Ballesteros, pero nació en Pest y era cura del hospital de Mistelbach prestando consuelo espiritual para los enfermos.

El escudo Rodriguez bordado, cuyo reverso contiene la inscripción Arma Rodriguez de la Rod, fue elaborada a principios del siglo XX. El atributo de Ballesteros y el escudo de los Rodriguez, que estaba en posesión de la familia, significaban el único punto de partida para seguir con la investigación en esta dirección. 


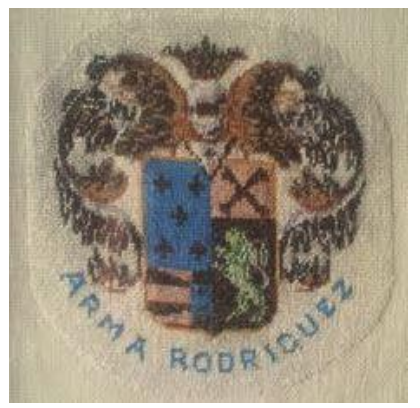

Tabla 11. El escudo Rodriguez

La localidad de Ballestero se encuentra en el municipio de Albacete, cuyo nombre viene del árabe. La Roda es otra localidad que se halla en Albacete, y que podría ser la procedencia de la escritura que se puede leer en el reverso del escudo. Las matrículas originales de La Roda se pueden consultar en versión digital en línea.

Salvo tres inscripciones, no hay rastro de Rodriguez Ballestero ni en Ballestero, ni en La Roda, o en cualquier otra localidad de Albacete. De estas tres inscripciones, la que probablemente hace referencia al ascendiente de la familia española que emigró a Hungría, se encuentra en la parroquia de la iglesia del San Salvador de La Roda.

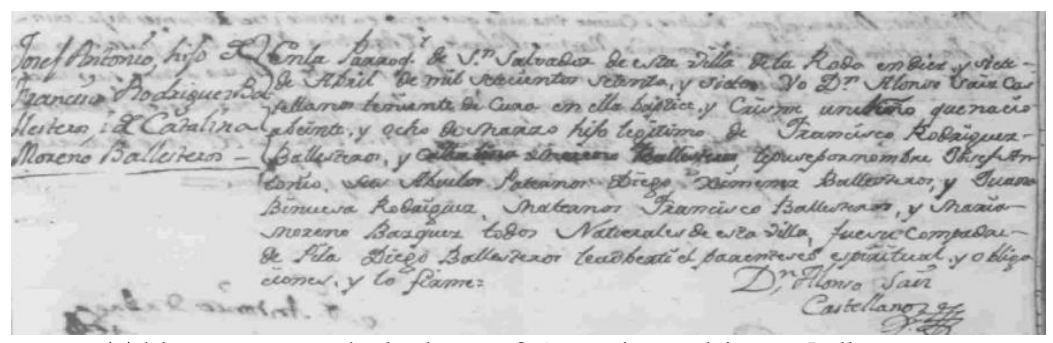

Tabla 12. La matrícula de Josef Antonio Rodriguez Ballesteros

Según esta, Josef Antonio Rodriguez Ballesteros nació el 17 de abril de 1777 en la localidad de La Roda del municipio de Albacete. Su padre era Francisco Rodriguez Ballesteros y su madre Cathalina Moreno Ballesteros. Josef Antonio Rodriguez Ballesteros podía ser el padre de Antonio de Rodriguez, teniente del regimiento de Alcaudete, quien era el fundador de la familia Rodriguez del Banato. De este modo, los datos biográficos de Fulgentius Rodriguez también aportaron la posibilidad de la investigación de la historia familiar. 
La genealogía y vida del sacerdote Agustino Fulgentius Rodriguez del Banato

\section{Referencias bibliográficas}

Alcoberro, Agustí (2002). L'exili austriacista (1713-1747). En: Fundació Noguera Textos. Vol. II: document 36.

Anderle, Ádám (2013). Új Barcelona: város a Duna mentén? Kora Újkor, 87-92.

Barsi, Béla (2017). El origen de la familia Rodriguez del banato a través de la historia militar del siglo XVIII. El ascendiente español. Acta Hispanica, 22. 121-136.

Fallenbüchl, Ferenc (1943). Az ágostonrendiek Magyarországon. Sżent István Akadémia II. Tom. III.

Fallenbüchl, Zoltán (1979). Espagnols en Hongrie au XVIII siecle (II). Liste des noms Espagnols de Immigration vers le Banat et du refluxe vers Buda et Pest 1736-1748. Revista de Archivos, Bibliotecas y Museos 82.

Fallenbüchl, Zoltán (1977). Spanyolok Magyarországon a XVIII. században. Századok, 6. 1992-1230.

Fallenbüchl, Zoltán történetírói hagyatéka Fővárosi Levéltár HU XIV. 67.

Family History Library Catalog. Carrete de película No. 7993450, imagen No. 349.

MNLOL (Magyar Nemzeti Levéltár Országos Levéltára), Protocollum Exhibitorium C2, Carrete de película No. 19259.

MNLOL, Acta Generalia, Documento con el número de referencia A-39/1285.

Miletz, János (1878). Adatok a délmagyarországi spanyol telepek történetéhez. Délmagyarországi Történelmi és Régészeti Múreum-Társulat Értesitóje. IV. 75-86.

Réti, László (1890). Magyarországi spanyol telepek. Ethnographia. 1. 300-302.

Tropper, Christine. Archiv der Diözese Gurk Zl: A-98106.

Tropper, Peter. Comunicado del Diócesis de Klagenfurt ,12 de junio de 2018.

Weißensteiner, Johann (2018). Archivo de la Diocésis de Viena. Personalstand der Sek.-und Reg-Geistlichkeit der Fürsterbishcöflichen Wiener-Disözese, 1837, und personalstand der Konz. Und der. Gesamten Welt-und Klosters, 1837.

Traducido por Orsolya Bíró

86 | Acta Hispanica (2019) 24 